\title{
RANGE AND IMAGE BASED MODELLING: A WAY FOR FRESCOED VAULT TEXTURING OPTIMIZATION
}

\author{
G. Caroti, I. Martínez-Espejo Zaragoza, A. Piemonte \\ Dipartimento di Ingegneria Civile e Industriale, Università di Pisa, Largo Lucio Lazzarino 1 \\ 56123 PISA, phone 050221 7770, e-mail gabriella.caroti@ unipi.it
}

\author{
Commission V, WG V/4
}

KEY WORDS: Structure From Motion, Laser scanning, Photogrammetry, Cultural Heritage, Texture, Precision

\begin{abstract}
:
In the restoration of the frescoed vaults it is not only important to know the geometric shape of the painted surface, but it is essential to document its chromatic characterization and conservation status. The new techniques of range-based and image-based modelling, each with its limitations and advantages, offer a wide range of methods to obtain the geometric shape. In fact, several studies widely document that laser scanning enable obtaining three-dimensional models with high morphological precision. However, the quality level of the colour obtained with built-in laser scanner cameras is not comparable to that obtained for the shape. It is possible to improve the texture quality by means of a dedicated photographic campaign. This procedure, however, requires to calculate the external orientation of each image identifying the control points on it and on the model through a costly step of post processing. With image-based modelling techniques it is possible to obtain models that maintain the colour quality of the original images, but with variable geometric precision, locally lower than the laser scanning model. This paper presents a methodology that uses the camera external orientation parameters calculated by image based modelling techniques to project the same image on the model obtained from the laser scan. This methodology is tested on an Italian mirror (a schifo) frescoed vault. In the paper the different models, the analysis of precision and the efficiency evaluation of proposed methodology are presented.
\end{abstract}

\section{INTRODUCTION}

In geomatics, current surveying techniques and methodologies allow obtaining the shape of an object by means of dedicated hardware and software procedures. When applied in the field of historical-architectural heritage, such procedures can provide an exact geometric record of the de facto state of the object. Documentation for cultural heritage often requires 1:50, and sometimes 1:20, rendering. Such rendering scale allow for a detailed analysis of the morphological features of the object (Batini, 2014).

In time, many research groups have studied the accuracy and the precision of the obtainable 3-D models (Adembri et al., 2011; Benedetti et al., 2010; Biosca Taronger et al., 2007; Guidi et al., 2010; Guidi \& Remondino, 2012; Juan Vidal \& MartínezEspejo Zaragoza, 2011; Merlo et al., 2013; Verdiani, 2011; Wenzel et al., 2013).

These new investigating technologies are extensively used both globally, for the survey of the historic architectural complex as a whole, and locally, for the survey of the decorative and architectural details. Among them, the painted decorations (frescoes, surface paintings in general, etc.) are perhaps the most significant, but possibly more fragile, elements, receiving the constant attention of all the figures that in various capacities are involved in the planning and implementation of restoration and conservation (architects, administrators, engineers, art historians, restorers, etc.).

While in the past restoration techniques for pictorial works were based on traditional visual inspection, nowadays, with the availability of new digital technologies it is possible to achieve objective, three-dimensional, geometrically accurate data, to which all results of different types of investigation can be referred. New technologies have therefore given a strong boost to digital cataloguing, documentation and monitoring of the preservation state of painted decorations, so that the availability of virtual models is now an essential tool in the development of heritage rendering.

It seems clear, therefore, that it is exactly in the transition phase from cognitive/investigative to operational that new technologies are required to interface and integrate with traditional techniques.

In 3-D renderings, chromatic data are often confined to the final popularization phase, i.e. colouring a simplified model. In fact, this appears as a demeaning of 3-D models as tool of scientific representation (Cipriani et al., 2014).

This research stems from the pressing need of restorers to have models high in precision and quality, in term of both geometry and texture colour. In this context, this work proposes a study of various techniques to apply high quality colour textures to laser scanner based models featuring high precision for topology and morphology.

\section{STATE OF THE ART}

\subsection{Geometry survey}

Laser scanning is currently an established surveying technique, whose accuracy and resolution are suitable for the rendering of historical, archaeological and architectural heritage aimed at classification and restoration (Bevilacqua et al., 2012; Caroti \& Piemonte, 2008; Caroti \& Piemonte, 2012; Dore and Murphy, 2012; Juan Vidal \& Martínez-Espejo Zaragoza, 2011; Lerma et al., 2011; Marambio et al., 2009; Martínez-Espejo Zaragoza and Juan Vidal, 2012). An obvious advantage is the maximization of the ratio between the amount of data and survey duration. On the other hand, a major drawback is the high cost of both hardware and software, as well as the burdensome postprocessing phase (nine days of in-house processing for each 
single day of field survey to achieve a high resolution textured model).

Over the last decade, a new methodology for 3-D surveying, by means of images, based on Structure from Motion (SfM) algorithms, has been gradually spreading. Using this computer vision technique the geometric structure of the $3 \mathrm{D}$ scene and the pose of the camera at each image can be quickly recovered from a series of overlapping, offset images. (Alsadik et al., 2013; Guidi et al., 2010; Guidi \& Remondino 2012; Koska \& Kremen, 2013; Lerma et al., 2010; Rodriquez 2012; Wenzel et al., 2013). This new approach to softcopy photogrammetry generates very dense $3 \mathrm{D}$ colour point clouds quite similar in size to the one produced from laser scanning surveys.

However, even if the software evolution in this field is very rapid and performance in terms of processing time, amount of manageable data and obtainable precisions is gradually improving, these proceduresmay not always be considered reliable. In fact, they suffer from variable precision, strongly dependent on the pattern present on surveyed objects, as well as the difficulty of having little control of the achievable accuracy at the geometric and morphological levels (Apollonio et al., 2014; Guidi \& Remondino, 2012).

\subsection{Texture mapping}

In large scale 3-D models used as supporting documentation in restoration works, textures are not a mere aesthetic complement. In fact, in addition to supporting construction, material and chromatic studies, they also act as metric surveying tools, providing, once applied to the models, a guideline for measurements.

Therefore, if textures have to meet these requirements, their positioning accuracy must be consistent with the scale used, besides having the necessary chromatic precision.

Many laser scanners have built-in cameras, whose relative orientation is calibrated by the manufacturer, which allow direct true colouring of the point cloud. These textures are characterized by a high geometric accuracy, but the systems used for the photographic takes usually do not achieve good results in terms of resolution and colour fidelity (Apollonio \& Remondino, 2010)

Simplified, realistic-looking models may not suffice for restorers, who require rigorous texture mapping for both morphology and colour information.

In these cases, it is essential to resort to a dedicated photographic campaign, performed with high quality cameras as regards optics, sensor size and post-processing graphics.

The traditional way to obtain textures from these photos is to derive camera orientation parameters from a single take, generate the UV map using so-called texture mapping of the projection of the single-frame model (Apollonio et al., 2010; Baldissini et al., 2010; Guidi et al., 2010) and finally merge the different partial UV maps to generate the texture of the model as a whole. Textures obtained in this way allow obtaining 3high quality D models in terms of geometric, morphological and chromatic aspects (Fantini et al., 2012).

On the other hand, this procedure is very time-consuming, also requiring constant operator intervention in the collimation of the points on the model and on images. In addition, software and procedures commonly used quite often do not take into account the distortion present on images.

In the case of SfM software, the creation of models and textures is pretty much contextual, and the procedure usually involves self-calibration of the camera, which also takes account of characteristic distortion parameters. In these models, textures usually have good photographic quality, although, as stated in section 2.1, the overall morphological reliability of such models is not comparable to laser derived ones.

\section{MATERIALS AND METHODS}

Laser scanning models are quite accurate and detailed as regards geometry and morphology. On the other hand, the quality of pictures taken by the built-in camera is altogether substandard, hence textures need to be obtained by photographs taken with a reflex camera.

The traditional way to obtain a texture is to project the singleframe take on the model, and then merge the different partial UV maps to generate the texture of the overall model.

Models derived by the SfM methodology, although providing good rendering of the vault as a whole, cannot ensure homogeneous accuracy in rendering small morphological variations, due to their dependency on the vault surface pattern. Higher deviations coincide with cracks, the borders of collapsing plaster and gaps in frescoes, all important features for restorers. On the other hand, the colour quality of the texture is quite good, as it is in direct relation with the quality of the images used for texture application.

\subsection{The case study}

The case study is a frescoed vault on the ground floor of Palazzo Roncioni, in Pisa. The vault is a type rather common in Italy known as a schifo or mirror vault, having a not quite regular rectangular plan. The fresco, painted by Tuscan painter Giovan Battista Tempesti, is largely preserved, though it presents some obvious recent gaps due to environmental degradation.

\subsection{Survey}

This vault has been surveyed by Leica Geosystems' C10 ScanStation laser scanner, fitted with a built-in camera. The resolution of the survey was set at $4 \mathrm{~mm}$ at $10 \mathrm{~m}$, resulting in a very dense cloud (on average $70 \mathrm{pts} / \mathrm{cm}^{2}$ ). In order to simplify the model where surfaces were smooth, a decimation of the points was performed, preserving in any case the geometrical information that, however small, is valuable for restorers (local deformation, cracks, ...).

In order to texture the derived model with more faithful colours, a dedicated photographic campaign was performed using a Nikon D700 camera fitted with a fixed $20 \mathrm{~mm}$ objective. The shooting distance was on average $4.5 \mathrm{~m}$, which allowed single pixel coverage of about $2 \mathrm{~mm}$. Furthermore, an additional photographic campaign, designed for subsequent threedimensional modelling via SfM methodologies, was carried out. This is necessary because, while for texturing, as described above, the images are just required to cover the entire surface, ensuring a low mutual overlap, SfM software requires a large overlap between consecutive images to allow better matching results (in general better than $70 \%$ ). The new photo campaign was carried out with the same camera and the same optical system as the previous one.

\subsection{Laser scanner model texturing by means of individual images}

In the photographic draft take the surface of the vault was divided in areas, characterized by almost constant curvature, in each of which photographic images were acquired, keeping the 
optical axis close to the direction of the radius of curvature of the centroid of each area. The images must ensure full coverage of the object taking into account that only the central portion of each image is used in order to avoid residual radial distortion at the edges.

The processing procedure is the same for each image to be projected. Considering the portions in common between the image and the 3-D model obtained from the laser scanner, a set of tie points was chosen, maintaining the distribution as uniform as possible. These points have been exported as coordinates in DXF format, using a point cloud management software of the laser model. These coordinates constitute the control points, which the photogrammetric software uses to orient the image. Photogrammetric software is used to derive the image coordinates of the chosen tie points; it is also possible to calculate the camera image features along with the precision with which the various parameters were determined.

Repeating this process for all the images yields the orientation parameters of the cameras, each of which is exported in a format compatible with the entertainment software used for texturing (e.g. Luxology Modo - format * .fbx).

In order to texturize the model, once it has been imported into the entertainment software, the so-called subdivision surfaces model must be created (Fantini, 2012) and the related UV map defined (Fig. 1).

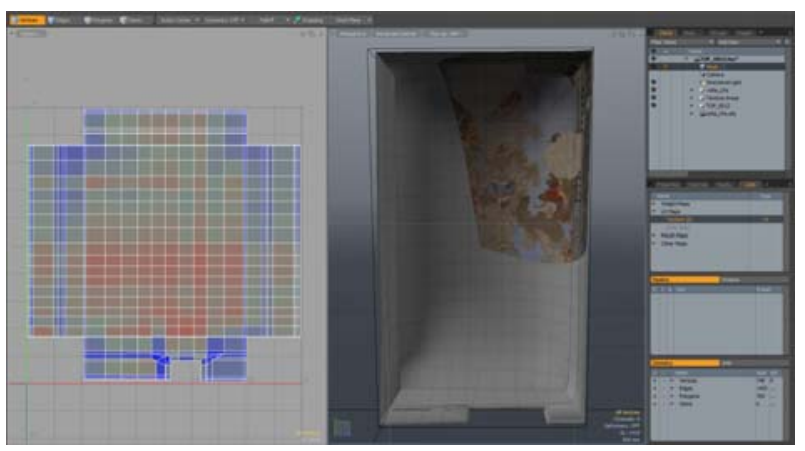

Figure 1. Projection of single image on the laser scanner model.

By projecting individual image partial UV maps are obtained for each one (Fig. 2 left), where colour is applied only to the framed part of the vault. At this point, all partial UV maps have to be reprocessed with an image editor (e.g. Photoshop) in order to merge them into a single image (Fig. 2 right). This operation requires processing the different images to produce uniform brightness, contrast and saturation and to select the portions of the partial UV map corresponding to the central portion of the respective image to reduce the influence of the residual radial distortion. Finally, the overall UV map is projected onto the laser model using entertainment software.

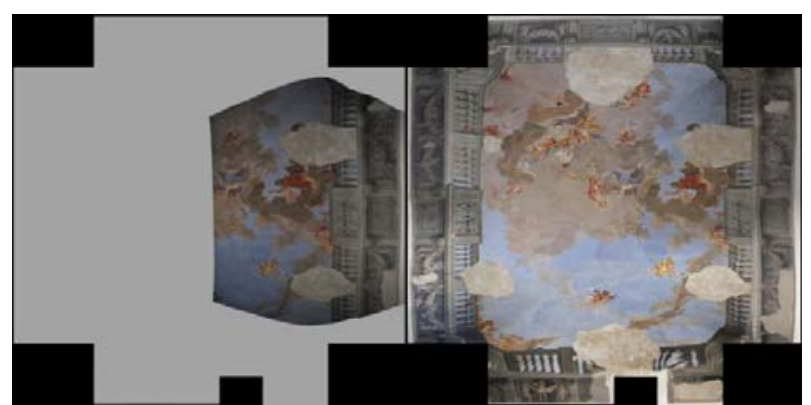

Figure 2: Partial UV map of a single image (left) and total overall UV map (right).

\subsection{Model from SfM}

A dedicated photographic campaign with high percentage of overlap along both axes has been performed in order to produce a set of images suitable for application of the SfM modelling methodology. The images have been processed via Agisoft's PhotoScan 1.0.0 software. This is quite common commercial software that enables performing the different steps needed for Image-Based Modelling: camera calibration, automatic detection of homologous points, image orientation, extraction of a dense point cloud, input of control points and absolute orientation of the model, surface generation and texture mapping (Manferdini \& Remondino 2010).

The output is a 3-D model with good chromatic quality (Fig. 3 left). On the other hand, the precision of the underlying geometry (Fig. 3 centre) is not as good as that obtained with laser scanning-based surveys (Fig. 3 right).
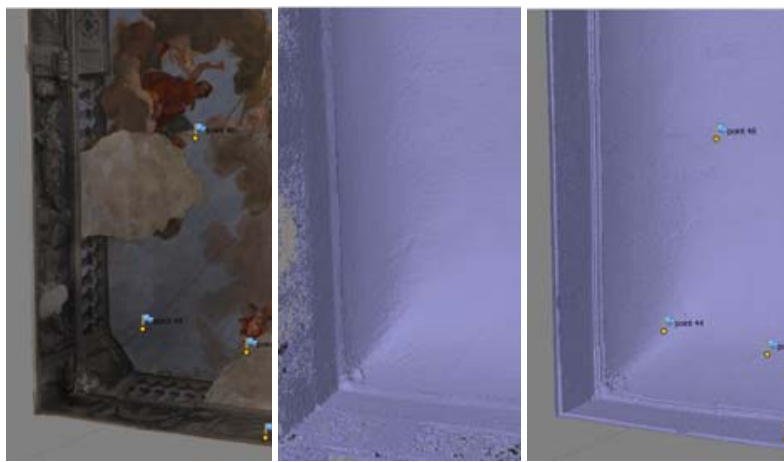

Figure 3. Texture from SfM (left); model from SfM (centre); model from laser scanning (right).

\subsection{Laser scanner model texturing by means of SfM oriented images}

The models obtained via laser scanning and SfM have been framed in the same reference system by means of 30 tie points evenly spread across the vault.

This has allowed using the external orientation of the cameras used for SfM-processed images to project the same images on the laser scanning model rather than on the SfM (Fig. 4).

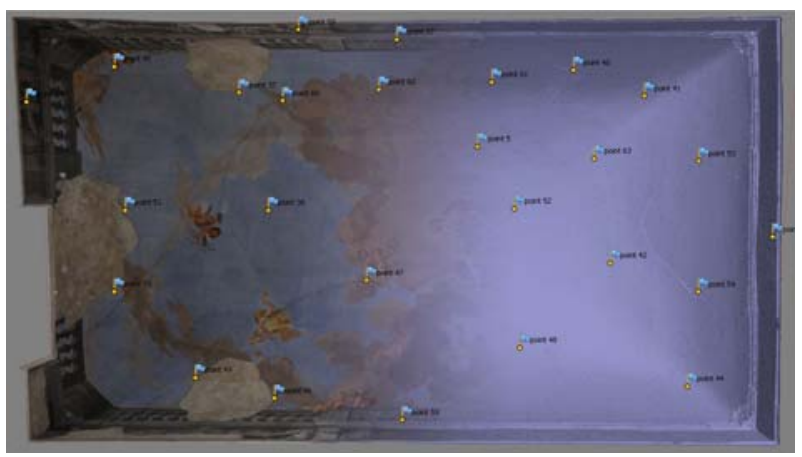

Figure 4. Laser scanning model textured by images oriented with SfM technology. 


\section{RESULTS AND DISCUSSION}

The textured model was then checked for precision and quality. Effectiveness in terms of resources and time required for the different processing types has also been assessed.

\subsection{Laser scanner model texturing by means of individual images}

In order to apply the texture to the laser derived model, thirty tie points (on average) have been chosen on each image and on the model. The standard deviation following the image orientation procedure averaged 4 pixels. The texture applied to the model does not show any discontinuity in the transitions between images; moreover, its precision has also been checked by printing at a 1:1 scale on acetate paper and directly comparing them with the object (Fig. 5). This model can then be assumed as a reference also in assessing the positioning precision of the texture.

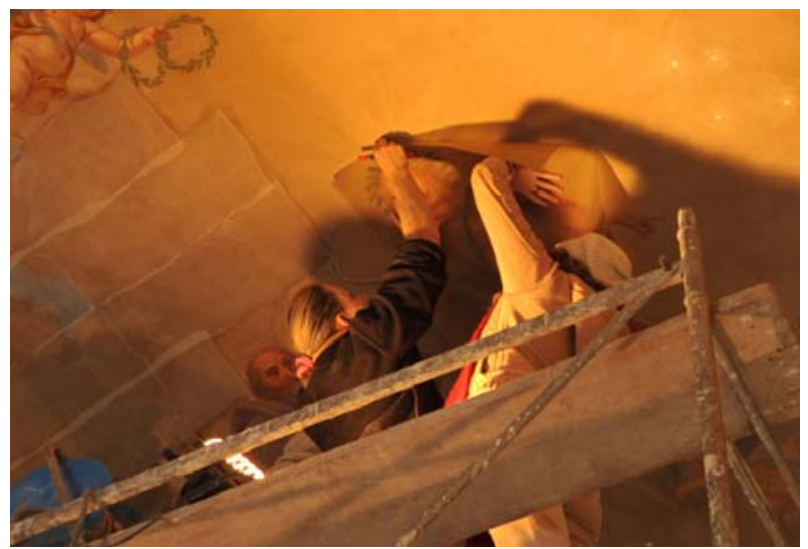

Figure 5. Precision check at 1:1 scale.

On the other hand, it must be noted that completion of the processing step, including image orientation and blending, took five person-days of work.

\subsection{Geometrical comparison between laser- and SfM- derived models}

The present research aims to use image orientation obtained by $\mathrm{SfM}$ to project the same images over a laser scanning derived model. Therefore, it was necessary in the first place to check the precision of the model obtained by SfM for an indirect assessment of image orientation.

Point-to-point deviations of the SfM model have been measured using the laser scanning model as a reference. This check performed on the whole model resulted in a standard deviation of about $3 \mathrm{~mm}$. These results show that image orientation is substantially accurate and confirmed the mean reprojection error involved with orientating each image via SfM to be 0.70 pixel with an average of 9000 tie points per image. On the other hand, maximum deviation values are in the range of $7-10 \mathrm{~mm}$ and refer to cracks, plaster collapse borders and gaps in the fresco. Figures 6 to 11 show an overview of the fresco and some details on local deviations.

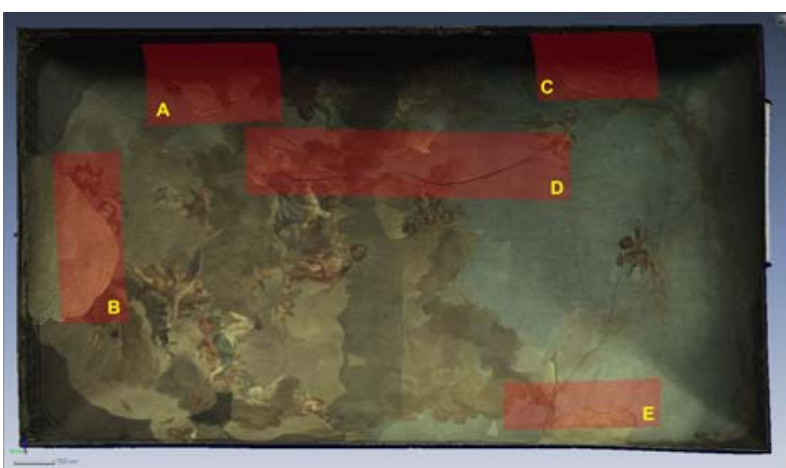

Figure 6. Regions checked for deviations between laser scanning- and SfM-derived models.

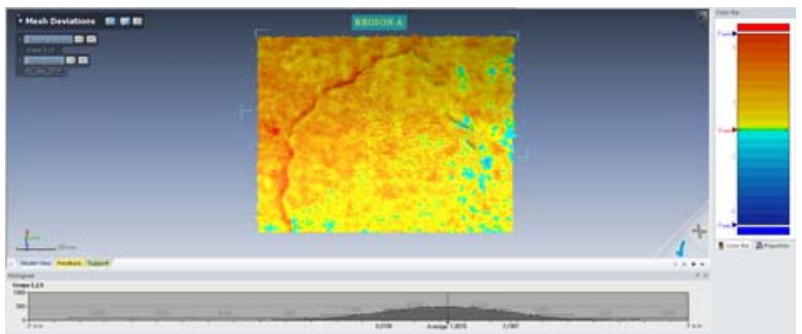

Figure 7. Region A: total plaster collapse borders.

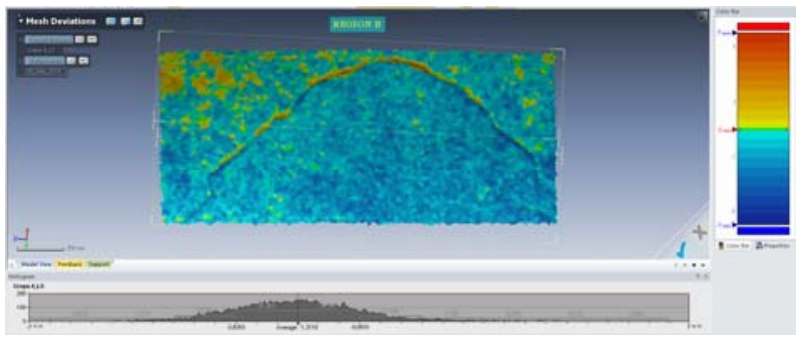

Figure 8. Region B: total plaster collapse borders.

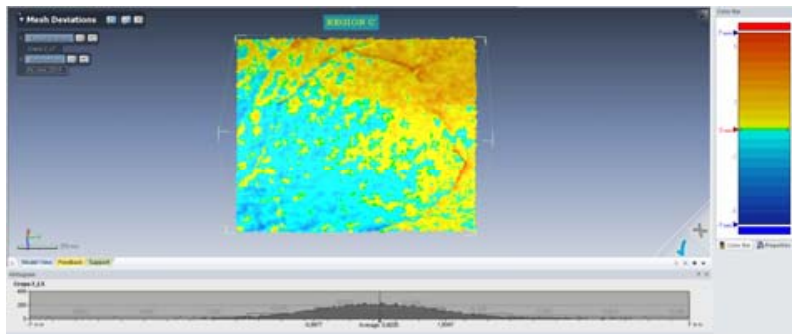

Figure 9. Region C: gap in the fresco.

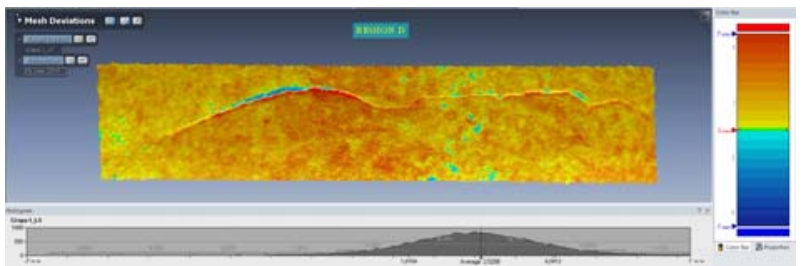

Figure 10. Region D: crack in the topmost region of the vault. 


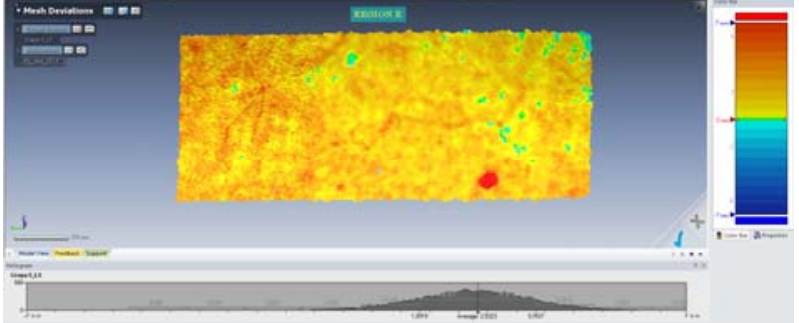

Figure 11. Region E: gap in the fresco.

Hence, the SfM-derived model is overall quite exact, but shows some flaws precisely in the regions of most interest to restorers. This processing methodology, on the other hand, has the advantage of significantly lower resource requirements: manual intervention is limited to inputting the support points to orient and scale the model, and the entire process required only person-day of work.

\subsection{Texture precision of final model}

The geometry of the final model is derived from the laser scanning survey. The texture of the model has been obtained via SfM software by importing the model and projecting the oriented images. The precision check for texture positioning was performed by measuring point-to-point deviations between easily identifiable features on the SfM and the laser scanner textures, which resulted in a standard deviation of about $3.5 \mathrm{~mm}$.

\section{CONCLUSIONS}

This paper presents a methodology that uses external orientation of images computed with SfM techniques to project the same images on the model derived from laser scanning.

For data integration purposes, the models generated by both methodologies are compared. The comparisons substantially confirm the good overall accuracy of camera orientation obtained by SfM. The comparison between the models is subsequently elaborated on through an precision check by means of tie points and analysis of the different processing methodologies.

The proposed methodology allows obtaining a threedimensional model which retains the geometric precision of laser scanning surveys along with the texture quality obtainable with a photographic survey campaign.

The most interesting feature of the proposed methodology lies in the considerable reduction in the necessary time and computing resources as compared to the traditional methodology of orientation and projection of single images on the model. Finally, regarding texture positioning precision, both procedures have yielded results of the same order of magnitude.

\section{REFERENCES}

Adembri, B., Juan Vidal, F., Martínez-Espejo Zaragoza, I., 2011. "Hunting friezes of the Piazza d'Oro at the Hadrian's Villa: new hypothesis for a virtual reconstruction inside an integrated research strategy" in Proceedings 16th International Conference on Cultural Heritage and New Technologies. Museen der Stadt Wien - Stadtarchäologie. Vienna. ISBN: 9783-200-02740-4, pp.140-153.

Alsadik, B., Remondino, F., Menna, F., Gerke, M., Vosselman, G., 2013. "Robust extraction of image correspondences exploiting the image scene geometry and approximate camera orientation" in The International Archives of the Photogrammetry, Remote Sensing and Spatial Information Sciences, Vol. XL-5/W1.

Apollonio, F.I., Baldissini, S., Manferdini, A.M., Remondino, F., 2010. "Rilievo 3D nell'area archeologica di Pompei: risultati e considerazioni." in Modelli Digitali $3 D$ in archeologia: Il caso di Pompei. Edizioni della Normale. Scuola Normale Superiore Pisa, pp. 270-307.

Apollonio, F.I., Ballabeni, A., Gaiani, M.,Remondino, F., 2014. "Evaluation of feature-based methods for automated network orientation." in The International Archives of the Photogrammetry, Remote Sensing and Spatial Information Sciences, Vol. XL-5.

Apollonio, F.I. \& Remondino, F., 2010. "Modellazione 3D da sensori attivi Pipeline con laser scanner" in Modelli Digitali 3D in archeologia: Il caso di Pompei. Edizioni della Normale. Scuola Normale Superiore Pisa, pp. 94-117.

Baldissini, S., Gaiani, M., Remondino, F., 2010. "Rilievo, gestione e mappatura del colore" in Modelli Digitali $3 D$ in archeologia: Il caso di Pompei. Edizioni della Normale. Scuola Normale Superiore Pisa, pp. 200-235.

Battini, C., 2014. "Il colore come strumento di rilievo tridimensionale" in Colore e Colorimetria. Contributi Multidisciplinari, Vol. X A, Atti della Decima Conferenza del Colore, ISBN 978-88-916-0437-8.

Benedetti, B., Gaiani, M., Remondino, F. (ed.), 2010. Modelli Digitali 3D in archeologia: Il caso di Pompei. Ed. della Normale. Scuola Normale Superiore Pisa.

Bevilacqua, M.G., Caroti, G., Piemonte, A., 2012. "Rilievi integrati della Basilica romanica di San Gavino a Porto Torres", in Proceedings $16^{\circ}$ Conferenza Nazionale ASITA. VICENZA, p. 391-396, ISBN 978-88-903132-7-1

Biosca Taronger, J.M., Navarro Tarín, S., Lerma García, J.L., 2007. "Modelado tridimensional de una bóveda barroca mediante la combinación de láser escáner y fotogrametría", in 7 Setmana Geomàtica, Febrero 20-23, Barcelona, España.

Caroti, G. \& Piemonte, A., 2007. "Laser scanner and photogrammetry for the survey of Monumental Cemetery in Piazza del Duomo, Pisa (Italy)." in The International Archives of the Photogrammetry, Remote Sensing and Spatial Information Science, vol. XXXVI part 5/C53; p. 201-206, ISSN: 1682-1750.

Caroti, G. \& Piemonte, A., 2008. "An integrated survey for knowledge and preservation of a cultural heritage: the albanian fortified citadel of Elbasan.", in The International Archives of the Photogrammetry, Remote Sensing and Spatial Information Sciences, vol. XXXVII, part B5/V; p.373-378, ISSN: 16821750

Caroti, G. \& Piemonte, A., 2012. "Studio relativo al rilevamento di dettaglio di una porzione del transetto nord della chiesa di San Paolo a Ripa d'Arno al fine di procedere al consolidamento strutturale", in Proceedings Un incontro informale per i 70 anni del Prof. Carlo Monti, pp. 1-6, Edizioni SIFET, ISBN 978-88-905017-6-1. 
Cipriani, L., Fantini, F., Bertacchi, S., 2014. “Affidabilità ed ottimizzazione del texturing del colore apparente dei modelli da sensori attivi e passivi: casi studio nel settore dei Beni Culturali" in Colore e Colorimetria. Contributi Multidisciplinari, Vol. X A, Atti della Decima Conferenza del Colore, ISBN 978-88-916-0437-8.

Dore, C. \& Murphy, M., 2012. "Integration of Historic Building Information Modelling (HBIM) and 3D GIS for Recording and Managing Cultural Heritage Sites" in 18th International Conference on Virtual Systems and Multimedia (VSMM). VSMM 2012 Virtual Systems in the Information Society. 2 - 5 Septiembre 2012 Milan, Italia, pp. 369-376.

El-Hakim, S., Gonzo, L., Picard, M., Girardi, S., Simoni, A., 2003. "Visualization of frescoed surfaces: Buonconsiglio Castle - Aquila Tower, Cycle of the months" in ISPRS Archives - Vol. XXXIV-5/W10.

Fantini, F., 2011. "La modellazione in Displaced sub-D: Modelli a dettaglio variabile da scansione laser" in Il ritorno all'immagine, nuove procedure image based per il Cultural Heritage. ISBN 978-1-4452-9256-4.

Fantini, F., Rodríguez-Navarro, P., Di Tondo, S., 2012. "Il problema della mappatura del colore nei modelli digitali $3 \mathrm{~d}$ a displaced subdivision surface da rilevamento laser scanner in ambito archeologico" in Colore e colorimentria. Contributi multidisciplinari. Vol. VIII A. Dip. Indaco. Politecnico di Milano,pp. 31-38.

Guidi, G. \& Remondino, F., 2012. “3D Modelling from Real Data" in Modelling and Simulation in Engineering. Edited by Catalin Alexandru, InTech.

Guidi, G., Russo, M., Beraldin, J.A., 2010. Acquisizione 3D e modellazione poligonale. McGraw-Hill. Italia.

Juan Vidal, F. \& Martínez-Espejo Zaragoza, I., 2011. "Hypotesis for the virtual anastilosis of the main chapel of the Iglesia de Los Desamparados de Les Coves de Vinromá" in 16th International Conference on Cultural Heritage and New Technologies. Museen der Stadt Wien - Stadtarchäologie. Vienna. ISBN: 978-3-200-02740-4, pp.201-212.

Koska, B. \& Křemen, T., 2013. "The combination of laser scanning and structure from motion technology for creation of accurate exterior and interior orthophotos of St. Nicholas Baroque church" in The International Archives of the Photogrammetry, Remote Sensing and Spatial Information Sciences, Volume XL-5/W1.

Lerma, J.L., Navarro, S., Cabrelles, M., Villaverde V., 2010. "Terrestrial Laser Scanning and Close Range Photogrammetry for 3D Archaeological Documentation: the Upper Palaeolithic Cave of Parpalló As a Case Study" in Journal of Archaeological Science n.37. Elsevier, pp. 499-507.

Lerma, J.L., Cabrelles, M., Navarro, S., Seguí, A.E., 2011. “La documentación patrimonial mediante sensores de imagen o de barrido láser" in Documentación gráfica del patrimonio, Ministerio de Cultura,pp. 108-117.

Manferdini, A.M. \& Remondino, F., 2010. "Modellazione 3D da immagini. Pipeline fotogrammetrica" in Modelli Digitali 3D in archeologia: Il caso di Pompei. Edizioni della Normale. Scuola Normale Superiore Pisa, pp. 162-199.
Marambio, A., Pucci, B., Nuñez, M.A., Buill, F., 2009. "La aplicación del escáner láser terrestre en la catalogación del patrimonio arquitectónico del casco histórico de Castellfollit de la Roca" in VIII Semana Geomática Internacional,pp. 1-8.

Martínez-Espejo Zaragoza, I. \& Juan Vidal, F., 2012. “Gestión gráfica avanzada de edificaciones antiguas" in XI Congreso internacional de expresión gráfica aplicada a la edificación, Universidad Politécnica de Valencia. ISBN: 978-84-8363-9641.

Merlo, A., Fantini, F., Lavoratti, G., Aliperta, A., López Hernández, J.L., 2013. "Texturing and optimization of reality based digital models: the church of Compañía de Jesús" in DISEGNARECON. Vol. 6, n. 12.

Rodríguez Navarro, P., 2012. "La fotogrametría digital automatizada frente a los sistemas basados en sensores 3D activos" in Revista EGA (Expresión Gráfica Arquitectónica). Universidad Politécnica de Valencia. Valencia, pp.100-111.

Wenzel, K., Rothermel, M., Fritsch, D., Haala, N., 2013. "Image acquisition and model selection for multi-view stereo" in The International Archives of the Photogrammetry, Remote Sensing and Spatial Information Sciences, Volume XL-5/W1. 